\title{
PROPOSAL TO DESIGNATE STRAIN ATCC 3004 (IMRU 3004) AS THE NEOTYPE: STRAIN OF STREPTOMYCES ALBUS (ROSSI-DORIA) WAKSMAN AND HENRICI ${ }^{1}$
}

\author{
A. J. LYONS, JR. ANd T. G. PRIDHAM \\ Fermentation Laboratory, Northern Regional Research Laboratory,$^{2}$ Peoria, Illinois
}

Received for publication August 24, 1961

\section{ABSTRACT}

Lyons, A. J., JR. (Northern Regional Research Laboratory, Peoria, Ill.) and T. G. Pridham. Proposal to designate strain ATCC 3004 (IMRU 3004) as the neotype strain of Streptomyces albus (Rossi-Doria) Waksman and Henrici. J. Bacteriol. 83:370-380. 1962.- - It is proposed that strain ATCC 3004 (IMRU 3004) be designated henceforth as the neotype strain of Streptomyces albus (Rossi-Doria) Waksman and Henrici and as the type strain of the genus Streptomyces Waksman and Henrici. The proposal is based not only on the fact that the holotype strain [Streptotrix (sic) alba] of Rossi-Doria is no longer extant, but also on the fact that a study of the literature and a taxonomic study of 55 strains

1 The title of this paper, as presented at the 61st annual meeting of the American Society for Microbiology, was "Proposal to designate strain ATCC 618 as the neotype strain of Streptomyces albus (Rossi-Doria) Waksman et Henrici" (Bacteriol. Proc., p. 74, 1961). In the original preparation of the manuscript we obtained information that led us to believe that strains ATCC 618 and ATCC 3004 (IMRU 3004) were both descendants of one culture isolated about 1897 . Since presentation of the paper we have learned this is not true and have corrected the information. There is little doubt now that these two strains, while remarkably similar, did in fact originate from two different cultures. Because the history of strain ATCC 3004 (IMRU 3004) can be traced back to about 1897 , whereas strain ATCC 618 can be traced back to about 1914, we believe the former should have precedence in selection of a neotype strain and have changed the title and proposal as indicated. (ATCC refers to the American Type Culture Collection; IMRU refers to the culture collection of the Institute of Microbiology, Rutgers University).

${ }^{2}$ A laboratory of the Northern Utilization Research and Development Division, Agricultural Research Service, U. S. Department of Agriculture. of the organism indicate the species should exhibit these characteristics: catenulate ovoidal spores, white aerial mycelium, coiled sporophores, proteolytic activity, and nonchromogenicity (inability to form brown, deep brown, or black diffusible pigments). Strain ATCC 3004 (IMRU 3004) exhibits these characteristics, as do 16 other acquisitions. Study of the 16 additional strains that conform with the general definition of the species shows differences in some physiological characteristics. It is suggested that these differences are of subspecific significance.

Two different concepts have existed since 1916 with regard to Streptomyces albus (Rossi-Doria) Waksman and Henrici. One centers around strains with the following characteristics: flexuous sporophores, colors of aerial mycelium in tints and shades of olive-buff (yellowish gray or tan), nonchromogenicity (inability to form brown, deep brown, or black diffusible pigments in organic substrata), and marked abundance in nature. The other concept concerns strains that are characterized by coiled or spiralled sporophores with catenulate, ovoidal spores; by aerial mycelium colors generally interpreted as cretaceous (chalk-white, often with faint tinges of pink); by nonchromogenicity in organic substrata; and by their relative rareness in nature.

We believe the two issues can be clarified (Pridham and Lyons, 1961) by accepting the second concept, first proposed by Waksman and Curtis (1916) and stated as the concept of $S$. albus by Waksman and Henrici (1943) when designating it as the type species of the genus Streptomyces.

Waksman and Henrici additionally qualified their description of the species to include its ability to liquefy gelatin, to peptonize milk with production of an alkaline reaction, and to form an earthy or musty odor. 
We have continued our studies of 17 strains of $S$. albus (Pridham and Lyons, 1961) in more detail. Beyond the basic characteristics of the species, the 17 strains can now be segregated into two or more groups based on various physiological criteria. Moreover, a careful check of the histories of the strains has revealed that one of these groups contains descendants of only two strains. One was originally obtained by Berestnev (Berestneff or Berestnew), probably in the 1890 's. The other was isolated by Krainsky in 1914. In our opinion the cultures of this group are descendants of the earliest isolated and labeled cultures of S. albus still extant. Because the Berestnev culture was isolated at a much earlier date, we believe it should have precedence in selection of a suitable neotype strain.

No type strain of the Rossi-Doria culture was ever designated. Likewise, no neotype strain conforming to Waksman and Henrici's description was ever designated as the type of the species or the type of the genus. Waksman (1961) has designated a strain "IMRU 3005" as the "type" of the species, but this strain, originally isolated and described by Wollenweber (1920) as Actinomyces albus var. cretaceus, fails to conform with the Waksman and Henrici (1943) concept and actually is a member of the S. griseus group.

We intend to present a more detailed characterization of the group containing descendants of the Berestnev and Krainsky cultures (six strains), to propose that one of these strains, ATCC 3004 (IMRU 3004), be henceforth designated as the neotype strain of Streptomyces albus (Rossi-Doria) Waksman and Henrici, and to discuss briefly the characteristics of the remainder of the 17 strains studied.

\section{MATERIALS AND METHODS}

Strains studied. Of 17 strains that conform to the characteristics of S. albus, 6 are of particular importance. Their numbers and histories are:

Strain 618-1 was received in 1959 from the ATCC as ATCC 618. It is described in the ATCC catalog as having been received by the ATCC from A. J. Kluyver, Delft, Netherlands, in 1926. The culture was forwarded to the ATCC on oatmeal agar, along with a note stating that the culture was isolated by Krainsky and described in Centr. Bakteriol. Parasitenk., Abt. 2,
41:649, 1914. Kluyver received the strain from the Centraalbureau voor Schimmelcultures (CBS) on July 19, 1922. The CBS, in turn, had received it from Beijerinck in March 1918. The correspondence concerning this strain leaves little doubt that it was the original Krainsky strain.

Strain 618-2 was received in 1955 from R. Gordon, Institute of Microbiology, Rutgers University, as ATCC 618.

Strain 618-3 was received in 1955 from $\mathrm{T}$. Yamaguchi, Institute of Applied Microbiology, University of Tokyo, Japan, as ATCC 618.

Strain 3004-1 was received in 1959 from S. A. Waksman, Institute of Microbiology, Rutgers University as IMRU 3004. This strain was received in the 1920's by Waksman from the Pribram Collection (originally the Kral Collection) in Vienna, carrying the epithet label "albus" and with a note that it was named or isolated by Berestnew. A culture designated as Actinomyces albus Berestnew is listed in the Kral catalogues dated 1900 and 1902, and later in 1919 as a variety of A. saprophyticus (but still designated as $A$. albus Berestnev), with a note that it was isolated from straw in Prague.

Strain 3004-2 was received in 1956 from the ATCC as ATCC 3004. It was received by the ATCC from S. A. Waksman in 1944.

Strain 3004-3 was received in 1959 from the ATCC as ATCC 3004. It was received by the ATCC from S. A. Waksman in 1944.

Thus, the last three strains represent descendants of the Berestnev culture obtained by Waksman from the Pribram Collection.

Despite their different histories, the six strains described above are remarkably similar. They are hereinafter referred to collectively as the Berestnev and Krainsky strains. The histories of the remaining 11 strains were given by Pridham and Lyons (1961).

Procedures. Most of the general procedures used in this study have been described elsewhere (Committee on Bacteriological Technic, 1946; Subcommittee on the Taxonomy of the Actinomycetes, 1958; Küster, 1958; Gordon and Mihm, 1957; Gordon and Smith, 1955; Hesseltine, Benedict, and Pridham, 1954; Pridham and Gottlieb, 1948; Pridham, Hall, and Shekleton, 1951; Pridham, Hesseltine, and Benedict, 1958; Pridham and Lyons, 1961, Pridham et al., 
1956, 1957; Tresner and Danga, 1958; Waksman, 1919).

Stock cultures and inocula. All cultures prepared for the various observations, except for potato slants, originated from shaken-tube liquid preparations. The liquid inocula were prepared by transferring a loopful of spores from a 2-week-old sporulating culture, grown at 28 to $30 \mathrm{C}$ on tomato paste-oatmeal (TPO) agar slants or our formula for yeast-extract (YE) agar slants, into tryptone yeast extract (TYE) broth and incubated with shaking at 28 to $30 \mathrm{C}$ for $48 \mathrm{hr}$. All media were inoculated with an equal amount of these broth cultures.

Spore morphology and nature of spore surface. Spore morphology was determined by examination of Drechsler impression slides of strains that had been cultivated on inorganic salts-starch (ST) agar for 14 days at 28 to $30 \mathrm{C}$. The details of the method used were outlined by Pridham and Lyons (1961).

The nature of the spore surface of descendants of the Berestnev and Krainsky cultures has been reported in three publications (Pridham, 1959; Pridham and Lyons, 1961; Tresner, Davies, and Backus, 1961). Electron micrographs of two additional strains of $S$. albus, other than descendants of the Berestnev and Krainsky cultures, also have been made (Pridham and Lyons, 1961).

Morphology of sporophores. The morphology of sporophores of the strains was determined from examination of 14-day petri-dish cultures grown at 28 to $30 \mathrm{C}$ on ST agar, Czapek's solution (CZ) agar, glycerol-asparagine (GA) agar, and nutrient $(\mathrm{N})$ agar. $\mathrm{N}$ agar was prepared by adding the appropriate amount of agar ( $15 \mathrm{~g} /$ liter) to nutrient broth (Difco) and sterilizing for $20 \mathrm{~min}$ at $121 \mathrm{C}$.

Color. Methods for determination of colors of sporulating aerial mycelia, reverses of cultures, and diffusible pigments have been outlined elsewhere (Hesseltine, Benedict, and Pridham, 1954; Pridham, Hesseltine, and Benedict, 1958; Pridham and Lyons, 1961).

Colors of sporulating aerial mycelium, and reverses of cultures grown on ST, CZ, GA, and $\mathrm{N}$ agars were keyed by reference to Ridgway (1912). The Ridgway color designations were then converted to the Inter-Society Color Council-National Bureau of Standards (ISCCNBS) (Kelly and Judd, 1955) color number and name. Common color designations were used in recording the characteristics of the cultures grown on other media. No attempt was made to key colors of diffusible pigments when these occurred, because of difficulties experienced with this criterion in the past.

Proteolytic activity. The proteolytic activity of each of the strains was determined by five methods. These were: (i) cultivation in $12 \%$ plain gelatin (Difco) in tubes in which the inoculum ( $0.2 \mathrm{ml}$ of a $48-\mathrm{hr}$ TYE broth culture) was placed on the surface of the substratum. No stab was made. Cultures were incubated at 28 to $30 \mathrm{C}$ for 14 days. At 7 and 14 days, each culture was refrigerated at 3 to $5 \mathrm{C}$ for $1 \mathrm{hr}$ and examined for liquefaction and color of diffusible pigment; (ii) the Waksman $15 \%$ plain-gelatin dish method, with incubation at $18 \mathrm{C}$ (Waksman, 1919); (iii) the Waksman 15\% plain gelatin-1\% starch dish method, with incubation at $18 \mathrm{C}$ (Waksman, 1919); (iv) the skimmed-milk tube method, with incubation at 28 to $30 \mathrm{C}$ as outlined by the Subcommittee on the Taxonomy of the Actinomycetes (1958); and (v) the caseinplate method, with incubation at 28 to $30 \mathrm{C}$ (Gordon and Smith, 1955). Suitable uninoculated control media were used for comparisons.

All cultures were observed at 14 to 15 days, and the degree of liquefaction of gelatin, peptonization of milk, and clearing of casein agar was recorded.

Chromogenicity. The ability of the several strains to produce a brown, deep brown, or black diffusible pigment was determined by cultivation of each strain on international peptone (IP) agar (Pridham and Lyons, 1961) for 4 days at 28 to 30 C. Each strain was also cultivated on Dietz L-tyrosine water-agar slants for 14 days at 28 to $30 \mathrm{C}$. Directions for preparation of $\mathrm{L}$ tyrosine agar were given by the Subcommittee on the Taxonomy of the Actinomycetes (1958). At the end of the incubation period, each culture was examined for the presence or absence of diffusible pigment.

Ability to produce hydrogen sulfide. Each strain was cultivated on peptone iron agar (Difco), supplemented with $0.1 \%$ yeast extract (Difco), for 10 days at 28 to $30 \mathrm{C}$. Readings for presence or absence of the characteristic bluish black color of substrata, indicative of hydrogen sulfide production, were made at 1 and 10 days.

Ability to utilize various carbon sources for growth. Each strain was cultivated in petri 
dishes, containing the Pridham and Gottlieb (1948) basal agar supplemented with individual carbon compounds ( $D$-xylose, L-arabinose, rhamnose, D-glucose, D-fructose, sucrose, lactose, maltose, raffinose, D-mannitol, $i$-inositol, or salicin) each at a $1 \%$ level, for 10 days at 28 to $30 \mathrm{C}$. An appropriate control containing no carbon source was included. The plate method, a modification of the original tube method suggested, was outlined by the Subcommittee on the Taxonomy of the Actinomycetes (1958); 48-hr TYE broth cultures were centrifuged, washed twice with sterilized $0.85 \%$ saline solution, suspended in saline solution, and inoculated dropwise (ca. $0.05 \mathrm{ml}$ ). Three strains in duplicate were inoculated on the surface of each medium.

Ability to produce acid from various carbon sources. The ability of the strains to produce acid from D-xylose, D-mannose, maltose, and lactose was determined by Gordon and Smith's (1955) method. Observation of cultures was made after 14 days of incubation at 28 to $30 \mathrm{C}$, to determine whether acid had been produced.

Ability to reduce nitrates. The ability to reduce nitrate in both an organic-based medium and in a chemically defined medium was determined by procedures outlined by the Subcommittee on the Taxonomy of the Actinomycetes (1958) and by the Committee on Bacteriological Technic (1946). Cultures were tested and observed for reduction of nitrate after 14 days growth at 28 to $30 \mathrm{C}$.

Diastatic activity. Fourteen-day cultures of each strain grown on ST agar at 28 to $30 \mathrm{C}$ were examined for presence of clear areas adjacent to growth of the organism (indicating starch breakdown). Each dish culture was also flooded with ca. $2 \mathrm{ml}$ of Lugol's iodine solution and allowed to stand for several minutes. Disappearance of the blue color was considered evidence of starch breakdown.

Ability to decompose tyrosine and xanthine. Determination of the ability of the strains to decompose tyrosine and xanthine was made following methods outlined by Gordon and Smith (1955) and Gordon and Mihm (1957). Cultures were observed after 14 days incubation at 28 to $30 \mathrm{C}$ for clearing of the substrata as an indication of decomposition.

Cultural characteristics on potato slants. Cultural characteristics of strains grown on white potato slants were recorded after 14 days incubation at 28 to $30 \mathrm{C}$. Peeled white potatoes were cut as plugs, sliced as slants, and soaked in distilled water at 3 to $5 \mathrm{C}$ for $24 \mathrm{hr}$. The slants were drained, placed in test tubes, and sterilized for 15 to $20 \mathrm{~min}$ at $121 \mathrm{C}$. After sterilization, sterile distilled water was added to each tube to cover all but $1 / 4$ in. of the butt.

Each slant was inoculated with one loopful of spores from a 2-week-old culture grown on TPO agar or YE agar slants.

Acid fastness. The vegetative mycelium from 2-week-old cultures grown on GA agar was spread over a slide by use of a pipette with a rolling motion, fixed by flaming, and stained according to direction for the Ziehl-Nielsen method outlined by the Committee on Bacteriological Technic (1946). Prior to removal of vegetative growth, any aerial mycelium was removed by wiping the surface of the growth with a moist cotton pledget. Stained slides were examined under oil immersion at 1125 to $1800 \times$.

Optimal temperature range. Duplicate slants of TPO agar and YE agar were inoculated with 0.2 $\mathrm{ml}$ of a 48-hr TYE broth culture and incubated at $18,25,28,37,44$, and $55 \mathrm{C}$, respectively, for 14 days. At the end of the incubation period, the amount of growth was estimated and rated on a basis of +1 to +6 . Cultures grown at $28 \mathrm{C}$ were considered as a standard and recorded as +4 .

Ability to produce antibiotic factors. The antibiotic-producing capacity of each of the strains was determined by the Waksman agar-streak method, with Pridham and Gottlieb basal agar containing $1 \%$ D-glucose and $0.1 \%$ yeast extract (Difco), and by cultivation of each strain in shaken-flask fermentations with the Pridham and Gottlieb basal medium containing $1 \%$ Dglucose and $0.1 \%$ yeast extract and with a medium based on the medium A-4h of Warren, Prokop, and Grundy (1955) [soybean meal, $1.5 \%$ (Staley's 4-S); commercial glucose, $1.5 \%$ (Cerelose); distillers' dried solubles, $\mathbf{0 . 5 \%}$ (Curbay BG); glycerol, $0.25 \%$ wt $/ \mathrm{v} ; \mathrm{NaCl}$, $0.5 \% ; \mathrm{CaCO}_{3}, 0.1 \%$; distilled water; $\mathrm{pH}$ (after sterilization for $20 \mathrm{~min}$ at $121 \mathrm{C}) 6.70$ to 6.85 ]. For the agar streak tests, the strains were cultivated for 7 days at 28 to $30 \mathrm{C}$. Test bacteria, yeasts, molds, and streptomycetes were streaked at right angles to the streptomycete growth, and the dishes were held for an additional 3 to 5 
days at 28 to $30 \mathrm{C}$. At that time zones of inhibition were measured.

Shaken-flask media were inoculated with $1 \%$ (v/v) of a 48-hr TYE broth culture of the streptomycete. Seeded flasks were incubated on a rotary shaker at 28 to $30 \mathrm{C}$ for $192 \mathrm{hr}$. At 48 , 96, 144, and $192 \mathrm{hr}$, samples were removed aseptically and filtered through cheesecloth. The filtrates were assayed against nine test organisms by the paper-disc assay method. The test organisms used for the agar-streak determinations and the paper-disc assays were: Bacillus subtilis NRRL B-765; Staphylococcus aureus NRRL B-313; Escherichia coli NRRL B-766; Agrobacterium tumefaciens NRRL B-36; Erwinia carotovora NRRL B-204; Xanthomonas phaseoli NRRL B-1460; Mycobacterium sp. NRRL B-692; Saccharomyces pastorianus NRRL Y-139; Candida albicans NRRL Y-477; and Mucor ramannianus NRRL 1839. For paper-disc assays, the test organisms were grown in M-7 agar (Pridham et al., 1956), with the exception of M. ramannianus which was grown in MSA agar, a chemically defined medium (Pridham et al., 1956).

\section{RESULTS}

Spore morphology and nature of spore surface. The six strains originating from the Berestnev and Krainsky cultures all formed spores that were elongated and ovoid. In unstained preparations the spores measured 1.25 by $1.75 \mu$. In the Drechsler impression preparations, their diameters approximated $1.5 \mu$. The 11 other strains of $S$. albus that we have acquired also formed elongated, ovoid spores with these dimensions. Electron micrographs of representatives of the 17 strains indicate that the spores are smooth walled. The diameter of the aerial mycelium of the strains was approximately $1.5 \mu$ (Drechsler impression slide).

Morphology of sporophores. All 17 strains of S. albus were relegated to section Spira (Pridham, Hesseltine, and Benedict, 1958) after in situ observations of petri-dish cultures. The strains form small, compact to extended, coiled chains of spores. They occur on singly, oppositely branched, and sometimes verticillate branches. The verticillate aspect of these strains is quite different from that of forms which occur in the genus Streptoverticillium Baldacci, in that branching from the main axial hyphae is irregular and not equidistant. Also, the diameters of the axial hyphae of streptoverticillia are much greater than those of $S$. albus. Sporophores typical of the six Berestnev and Krainsky strains are illustrated in Fig. 1. A photomicrograph of another of the 17 strains has been presented elsewhere (Pridham and Lyons, 1961).

Color of aerial mycelium. Observations made of the Berestnev and Krainsky strains to determine the color of their aerial mycelia are presented in Table 1. The colors of aerial mycelium of the remaining 11 strains differed in no respect from those exhibited by the six strains. With the ISCC-NBS method of designating colors, the color of aerial mycelium would be: " 263 . white" and "73. pale orange yellow."

Color of reverse of cultures. Observations on the color of the reverses of the six strains are also presented in Table 1 . In addition to the Ridgway designations recorded in Table 1 , reverses of some of the remainder of the 17 strains of $S$. albus were Naples Yellow XVI, Pinkish Buff XXIX, and Honey Yellow XXX. With the ISCC-NBS method of designating colors, the reverses of the $S$. albus strains would be designated as: 28. light yellowish pink; 29 . moderate yellowish pink; 73. pale orange yellow; 86. light yellow; 87. moderate yellow; 88. dark yellow; 89 . pale yellow; 101. light greenish yellow; and 102. moderate greenish yellow.

Chromogenicity. None of the 17 strains of S. albus formed a brown, deep brown, or black diffusible pigment when grown on IP agar slant cultures for 4 days at 28 to $30 \mathrm{C}$. A very faint yellow diffusible pigment was noted with two of the strains that were not descendants of the Berestnev and Krainsky cultures. Cultures grown on Dietz $\mathrm{L}(-)$-tyrosine-water agar slants for 14 days at 28 to $30 \mathrm{C}$ produced either no diffusible pigment or very faint yellow to very faint yellowish-orange diffusible pigments in the case of the six Berestnev and Krainsky cultures. The remainder of the 17 strains showed some differences in color of diffusible pigment. Colors ranged from very faint yellow to reddish brown. Likewise, growth of the 17 strains in $12 \%$ plain gelatin for 14 days at 28 to $30 \mathrm{C}$ gave either no evidence of diffusible pigment production or evidence of only a faint yellow-brown diffusible pigment. It is concluded that the 17 strains are nonchromogenic within the limits of our definition of chromogenicity.

Production of hydrogen sulfide. None of the 17 

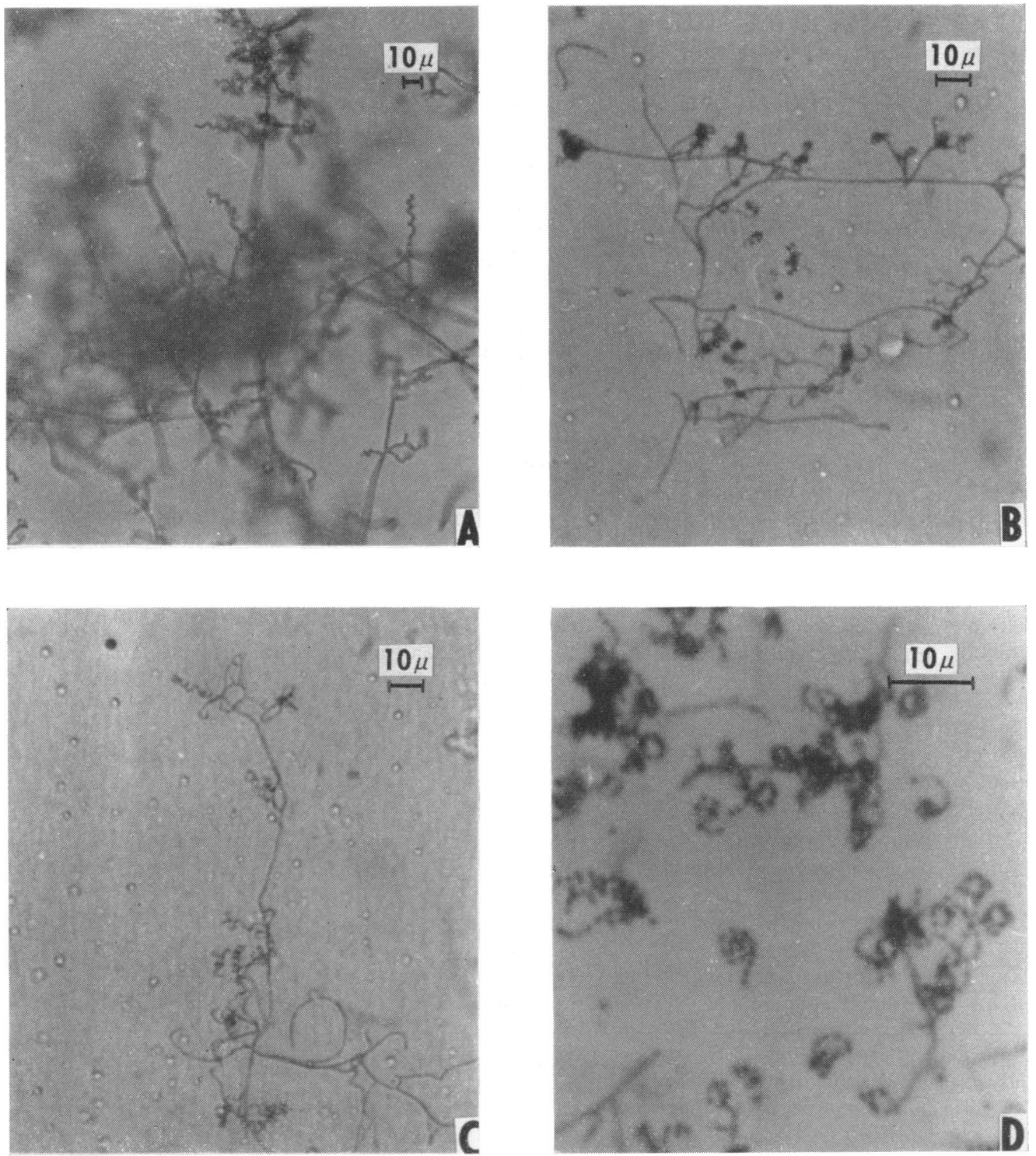

FIG. 1. Morphology of fruiting bodies of Streptomyces albus grown for 14 days at 28 to 30 C. A, Czapek's solution agar, in situ; $B$, inorganic salts-starch agar, cellophane impression slide, $C, C z a p e k$ 's solution agar, cellophane impression slide; $D$, inorganic salts-starch agar, Drechsler impression slide.

strains of $S$. albus produced the bluish-black coloration of substrata indicative of production of hydrogen sulfide, when cultivated on slants of peptone iron agar supplemented with $0.1 \%$ yeast extract for 10 days at 28 to $30 \mathrm{C}$. Readings were made at 1 and 10 days.

Proteolytic activity. When tested by the three methods used, all the 17 strains of $S$. albus liquefied gelatin. Tubes of $12 \%$ plain gelatin were completely liquefied after 14 days at 28 to $30 \mathrm{C}$. Diameters of zones of liquefaction on the Waksman $15 \%$ gelatin dish cultures ranged from 18 to $27 \mathrm{~mm}$; zones of the six Berestnev and Krainsky strains ranged from 18 to $24 \mathrm{~mm}$. Diameters of zones of liquefaction on the Waksman $15 \%$ gelatin-1\% starch dish cultures ranged from 16 to $22 \mathrm{~mm}$; zones of the six Berestnev and Krainsky strains also ranged from 16 to $22 \mathrm{~mm}$ diameter.

After cultivation of the 17 strains in skimmed 
TABLE 1. Colors of aerial mycelium and reverses of strains of Streptomyces albus grown for 14 days at 28 to $30 \mathrm{C}$

\begin{tabular}{|c|c|c|c|}
\hline $\begin{array}{c}\text { Designation } \\
\text { used }\end{array}$ & Medium* ${ }^{*}$ & Color of aerial mycelium & Color of reverse \\
\hline $618-1$ & $\begin{array}{l}\text { Czapek's solution agar } \\
\text { Inorganic salts-starch agar } \\
\text { Glycerol-asparagine agar } \\
\text { Nutrient agar }\end{array}$ & $\begin{array}{l}\text { Cretaceous } \\
\text { Cretaceous }\end{array}$ & $\begin{array}{l}\text { Cartridge Buff } \ddagger \\
\text { XXX } \\
\text { Cream Color XV } \\
\text { Pale Ochraceous } \\
\text { Buff XV } \\
\text { Straw Yellow XVI }\end{array}$ \\
\hline $618-2$ & $\begin{array}{l}\text { Czapek's solution agar } \\
\text { Inorganic salts-starch agar } \\
\text { Glycerol-asparagine agar }\end{array}$ & $\begin{array}{l}\text { Cretaceous } \\
\text { Near Pale Pinkish Buff } \\
\text { XXIX } \\
\text { Near Pale Pinkish Cinna- } \\
\text { mon XXIX } \\
\text { Cretaceous }\end{array}$ & $\begin{array}{l}\text { Ivory Yellow XXX } \\
\text { Cartridge Buff XXX } \\
\text { Cream Buff XXX }\end{array}$ \\
\hline $618-3$ & $\begin{array}{l}\text { Nutrient agar } \\
\text { Czapek's solution agar } \\
\text { Inorganic salts-starch agar } \\
\text { Glycerol-asparagine agar } \\
\text { Nutrient agar }\end{array}$ & $\begin{array}{l}\text { Cretaceous } \\
\text { Cretaceous } \\
\text { Near Pale Pinkish Buff } \\
\quad \text { XXIX } \\
\text { Cretaceous } \\
\text { Cretaceous }\end{array}$ & $\begin{array}{l}\text { Straw Yellow XVI } \\
\text { Cartridge Buff XXX } \\
\text { Cream Color XVI } \\
\text { Light Buff XV } \\
\text { Straw Yellow XVI }\end{array}$ \\
\hline $3004-1$ & $\begin{array}{l}\text { Czapek's solution agar } \\
\text { Inorganic salts-starch agar } \\
\text { Glycerol-asparagine agar } \\
\text { Nutrient agar }\end{array}$ & $\begin{array}{l}\text { No aerial mycelium formed } \\
\text { Near Pale Pinkish Cinna- } \\
\text { mon XXIX } \\
\text { No aerial mycelium } \\
\text { formed } \\
\text { No aerial mycelium } \\
\text { formed }\end{array}$ & $\begin{array}{l}\text { Near Marguerite Yellow XXX } \\
\text { Cream Color XVI } \\
\text { Light Buff XV } \\
\text { Massicot Yellow XVI }\end{array}$ \\
\hline $3004-2$ & $\begin{array}{l}\text { Czapek's solution agar } \\
\text { Inorganic salts-starch agar } \\
\text { Glycerol-asparagine agar } \\
\text { Nutrient agar }\end{array}$ & $\begin{array}{l}\text { Cretaceous } \\
\text { Cretaceous } \\
\text { Cretaceous } \\
\text { Cretaceous }\end{array}$ & $\begin{array}{l}\text { Cartridge Buff XXX } \\
\text { Cream Color XVI } \\
\text { Pale Ochraceous Buff XV } \\
\text { Straw Yellow XVI }\end{array}$ \\
\hline $3004-3$ & $\begin{array}{l}\text { Czapek's solution agar } \\
\text { Inorganic salts-starch agar } \\
\text { Glycerol-asparagine agar } \\
\text { Nutrient agar }\end{array}$ & $\begin{array}{l}\text { Cretaceous } \\
\text { Cretaceous } \\
\text { Cretaceous } \\
\text { Cretaceous }\end{array}$ & $\begin{array}{l}\text { Cartridge Buff XXX } \\
\text { Barium Yellow XVI } \\
\text { Cream Buff XXX } \\
\text { Straw Yellow XVI }\end{array}$ \\
\hline
\end{tabular}

* Formation of spores was verified on Czapek's solution agar and inorganic salts-starch agar but not on glycerol-asparagine or nutrient agars.

$\dagger$ Cretaceous or chalk-white indicates that no color tabs, other than "white," were equivalent to the color observed.

$\ddagger$ Ridgway color designations representing the closest approximation that could be made.

milk for 14 days at 28 to $30 \mathrm{C}$, reproducible results were not obtained. Three of the 17 strains failed to peptonize milk. Reproducibility with duplicate tubes for three other strains was not achieved. Of the six Berestnev and Krainsky strains, two failed to peptonize milk. Final pH's of the peptonized solutions ranged from 6.91 to 8.08 . The $\mathrm{pH}$ of control tubes was 6.60 .

All 17 of the strains of $S$. albus cleared the Gordon and Smith casein agar to about the same extent after cultivation for 14 days at 28 to $30 \mathrm{C}$.
It is concluded that the strains of $S$. albus studied exhibit good to excellent proteolytic capacity.

Utilization of carbon compounds. Apparently the 17 strains of $S$. albus exhibit a rather uniform carbon utilization pattern (Table 2).

Production of acid from carbohydrates. The results were not as uniform as those obtained in the carbon utilization study. Lactose was the only carbohydrate that allowed uniform acid production by all the strains (Table 3 ).

Nitrate reduction. Some differences were noted 
TABLE 2. Utilization of carbon compounds by strains of Streptomyces albus*

\begin{tabular}{|c|c|c|c|c|c|c|c|c|c|c|c|c|c|}
\hline Designation used & $\begin{array}{c}\text { Nega- } \\
\text { tive } \\
\text { control; } \\
\text { no } \\
\text { carbon }\end{array}$ & $\begin{array}{l}\text { D-Glu- } \\
\text { cose }\end{array}$ & $\begin{array}{c}\text { D-Xy- } \\
\text { lose }\end{array}$ & $\begin{array}{c}\text { L-Arab- } \\
\text { inose }\end{array}$ & $\begin{array}{l}\text { Rham- } \\
\text { nose }\end{array}$ & $\begin{array}{c}\text { D-Fruc- } \\
\text { tose }\end{array}$ & Sucrose & Lactose & Maltose & $\begin{array}{c}\text { Raffi- } \\
\text { nose }\end{array}$ & $\begin{array}{c}\text { D-Man- } \\
\text { nitol }\end{array}$ & $\begin{array}{c}i \text {-Inosi- } \\
\text { tol }\end{array}$ & Salicin \\
\hline $618-1$ & - & + & $\oplus$ & $(-)$ & $(-)$ & $\oplus$ & $(-)$ & + & + & $(-)$ & + & $(-)$ & + \\
\hline $618-2$ & - & + & $\oplus$ & $(-)$ & $(-)$ & $\oplus$ & $(-)$ & + & + & $(-)$ & + & $(-)$ & + \\
\hline $618-3$ & - & + & $\oplus$ & $(-)$ & $(-)$ & $\oplus$ & $(-)$ & + & + & $(-)$ & + & $(-)$ & + \\
\hline $3004-1$ & - & + & $\oplus$ & $(-)$ & $(-)$ & $(-)$ & $(-)$ & + & + & $(-)$ & + & $(-)$ & + \\
\hline $3004-2$ & - & + & $\oplus$ & $(-)$ & $(-)$ & $\oplus$ & $(-)$ & + & + & $(-)$ & + & $(-)$ & $\oplus$ \\
\hline $3004-3$ & - & + & $\oplus$ & $(-)$ & $(-)$ & $\oplus$ & $(-)$ & + & + & $(-)$ & + & $(-)$ & + \\
\hline CBS & - & + & $\oplus$ & $(-)$ & $(-)$ & $\oplus$ & $(-)$ & + & + & $(-)$ & + & $(-)$ & + \\
\hline F/3-1 & - & + & $\oplus$ & $(-)$ & $(-)$ & $\oplus$ & $(-)$ & + & + & $(-)$ & + & $(-)$ & + \\
\hline $\mathrm{F} / 3-2$ & - & + & $\oplus$ & $(-)$ & $(-)$ & $\oplus$ & $(-)$ & + & + & $(-)$ & + & $(-)$ & + \\
\hline $\mathrm{C}_{13} \mathrm{R}_{5-1}$ & - & + & + & $(-)$ & $(-)$ & $\oplus$ & $\oplus$ & + & + & $(-)$ & + & $(-)$ & $\oplus$ \\
\hline $\mathrm{C}_{13} \mathrm{R}_{5-2}$ & - & + & $\oplus$ & $(-)$ & $(-)$ & $(-)$ & $(-)$ & + & $\oplus$ & $(-)$ & + & $(-)$ & + \\
\hline $\mathrm{F} / 2$ & - & + & $\oplus$ & $(-)$ & $(-)$ & $\oplus$ & $(-)$ & + & + & $(-)$ & + & $(-)$ & + \\
\hline $\mathrm{A} / 7$ & - & + & $\oplus$ & $(-)$ & $(-)$ & $\oplus$ & $(-)$ & + & + & $(-)$ & + & $(-)$ & + \\
\hline $298 x$ & - & + & $\oplus$ & $(-)$ & $(-)$ & $\oplus$ & $(-)$ & + & + & $(-)$ & + & $(-)$ & + \\
\hline $299 \mathrm{x}$ & - & + & $\oplus$ & $(-)$ & $(-)$ & $\oplus$ & $(-)$ & + & + & $(-)$ & + & $(-)$ & + \\
\hline FAL H123 & - & + & $\oplus$ & $(-)$ & $(-)$ & $\oplus$ & $(-)$ & + & + & $(-)$ & + & $(-)$ & + \\
\hline $618-4$ & - & + & + & $(-)$ & $(-)$ & $\oplus$ & $(-)$ & + & + & $(-)$ & + & $(-)$ & + \\
\hline
\end{tabular}

* Pridham and Gottlieb basal agar, 10 days at 28 to $30 \mathrm{C}$. Symbols used: -, no growth; (-), faint growth. probably no utilization; $\oplus$, poor to fair growth; + , good growth and positive utilization.

in the relative abilities of the 17 strains to reduce nitrate, particularly with the organic-based medium (Table 4).

Diastatic activity. None of the 17 strains cleared inorganic salts-starch agar after incubation for 14 days at 28 to $30 \mathrm{C}$. Addition of Lugol's iodine to these cultures changed the color of the substrate to an intense purplish blue indicative of a starch-iodine reaction. It is concluded that the 17 strains possess little, if any, diastatic activity.

Tyrosine and xanthine decomposition. All 17 of the strains of S. albus cleared the Gordon and Smith $\mathbf{L}(-)$-tyrosine agar about the same after cultivation for 14 days at 28 to $30 \mathrm{C}$. Likewise, all 17 of the strains decomposed xanthine, but to markedly varying degrees. Some strains gave evidence of clearing the xanthine agar of Gordon and Mihm only directly beneath the vegetative growth. One of the Berestnev and Krainsky strains decomposed xanthine to this extent. The other five gave readily detectable zones of clearing around the growth.

Cultural characteristics on potato slants. The 17 strains of $S$. albus all formed a grayish-white aerial mycelium after 14 days growth on white potato slants at 28 to $30 \mathrm{C}$. The plugs were initially (after 3 days) a purplish-gray color, changing to a light brown after 14 days. Uninoculated control plugs also assumed the light brown color after 14 days. The initial purplishgray color of the plugs is attributed to decomposition of the potato by the organism and is similar to the coloration noted with potatoes just beginning to rot.

Acid fastness. All 17 strains of S. albus were nonacid fast when the Ziehl-Nielsen technique was applied to vegetative growth.

Optimal temperature range. Our studies indicate that the optimal temperature range for growth of the 17 strains of $S$. albus is $25 \mathrm{C}$ through $44 \mathrm{C}$. Although cultures incubated at $18 \mathrm{C}$ gave good growth, it was somewhat less than that obtained within the optimal range. Cultures incubated at $55 \mathrm{C}$ gave significantly less growth than those incubated within the optimal range. Uniform results were obtained with all strains within the range $25 \mathrm{C}$ through $37 \mathrm{C}$. At $44 \mathrm{C}$, strain differences became apparent, and readings ranged from +3 to +5 .

Antibiotic activity. When tested for capacity to produce antibiotics by the agar-streak and shaken-flask methods, the six Berestnev and Krainsky strains gave no evidence of producing antibacterial or antifungal factors. The remaining 
11 strains of $S$. albus produced antibiotic activity against at least two of the ten different test organisms. In some cases, as many as nine of the test organisms were affected.

Preliminary paper chromatographs of culture filtrates from these strains suggest that they all produce at least two antibacterial factors in common. Very few evidences of antagonism were noted when the 17 strains were studied simultaneously in cross-inhibition studies. The results suggest the possibility that the six Berestnev and Krainsky strains may, at one time, have possessed the capacity to produce the same antibiotic factors elaborated by the remaining 11 strains. The results also strengthen the suspicion that common factors are produced by the remaining 11 strains.

From the results of these studies we have concluded that the most practical course to take is that of proposing the designation of strain ATCC 3004 (IMRU 3004) as the neotype strain of $S$. albus. To that end a description of this strain is presented here.

TABLE 3. Production of acid from carbohydrates by strains of Streptomyces albus*

\begin{tabular}{|c|c|c|c|c|}
\hline Designation used & D-Mannose & D-Xylose & Maltose & Lactose \\
\hline 618-1 & $+\quad+$ & $+\quad+$ & $(-) \oplus$ & + \\
\hline $618-2$ & $+\quad+$ & $\oplus \oplus$ & $(-)(-)$ & + \\
\hline $618-3$ & $+\oplus$ & $\oplus \oplus$ & $(-) \oplus$ & + \\
\hline $3004-1$ & $+\oplus$ & $+\quad+$ & $\oplus \oplus$ & + \\
\hline 3004-2 & $(-)(-)$ & - & $\oplus(-)$ & + \\
\hline $3004-3$ & $\oplus+$ & $\oplus+$ & $\oplus(-)$ & + \\
\hline CBS & ++ & $(-)(-)$ & $(-)(-)$ & + \\
\hline $\mathrm{F} / 3-1$ & $\oplus \oplus$ & $\oplus \oplus$ & $\oplus(-)$ & + \\
\hline $\mathrm{F} / 3-2$ & $\oplus+$ & $\oplus+$ & $(-)(-)$ & + \\
\hline $\mathrm{C}_{13} \mathrm{R}_{5}-1$ & $(-)(-)$ & $\oplus \oplus$ & $\oplus \oplus$ & + \\
\hline $\mathrm{C}_{13} \mathrm{R}_{5}-2$ & & $-\quad-$ & $(-)(-)$ & + \\
\hline $\mathrm{F} / 2$ & $\oplus \oplus$ & $(-)(-)$ & $(-)(-)$ & + \\
\hline $\mathrm{A} / 7$ & $+\quad+$ & $(-)(-)$ & $(-)(-)$ & + \\
\hline $298 \mathrm{x}$ & ++ & $(-)(-)$ & $(-)(-)$ & + \\
\hline $299 \mathrm{x}$ & ++ & $(-)(-)$ & $(-)(-)$ & + \\
\hline FAL H123 & $\oplus \oplus$ & $-\quad-$ & $\oplus(-)$ & + \\
\hline $618-4$ & $\oplus \oplus$ & $\oplus \oplus$ & $(-)-$ & + \\
\hline
\end{tabular}

* Gordon and Smith 1955 method, 14 days at 28 to $30 \mathrm{C}$. Symbols used: + , marked acid production, indicator completely changed; $\oplus$, moderate acid production, indicator changed except for lower portions of slant; $(-)$, poor acid production, indicator changed slightly; -, no acid production, indicator unchanged. Results presented for two individual tubes for each strain and each carbohydrate.
TABLE 4. Reduction of nitrate by strains of Streptomyces albus*

\begin{tabular}{|c|c|c|c|c|}
\hline \multirow{2}{*}{ Designation used } & \multicolumn{2}{|c|}{$\begin{array}{l}\text { Chemically } \\
\text { defined broth }\end{array}$} & \multicolumn{2}{|c|}{ Organic-based broth } \\
\hline & Tube 1 & Tube 2 & Tube 1 & Tube 2 \\
\hline $618-1$ & - & - & $\oplus$ & $\oplus$ \\
\hline $618-2$ & $(-)$ & - & - & - \\
\hline $618-3$ & - & - & $\oplus$ & $\oplus$ \\
\hline $3004-1$ & - & - & - & - \\
\hline $3004-2$ & - & - & - & - \\
\hline $3004-3$ & - & - & - & - \\
\hline CBS & + & + & - & $(-)$ \\
\hline $\mathrm{F} / 3-1$ & + & + & - & - \\
\hline $\mathrm{F} / 3-2$ & + & + & - & - \\
\hline $\mathrm{C}_{13} \mathrm{R}_{5-1}$ & + & + & - & - \\
\hline $\mathrm{C}_{13} \mathrm{R}_{5-2}$ & + & + & + & - \\
\hline $\mathrm{F} / 2$ & + & + & + & + \\
\hline $\mathrm{A} / 7$ & + & + & + & $\oplus$ \\
\hline $298 x$ & + & + & $(-)$ & - \\
\hline $299 x$ & + & + & - & - \\
\hline FAL H123 & + & + & $\oplus$ & $\oplus$ \\
\hline $618-4$ & + & + & + & + \\
\hline
\end{tabular}

* Symbols used: - , nitrate not reduced; (-), very slight pink color produced on addition of reagents; $\oplus$, pale red color produced on addition of reagents; + , deep red color produced on addition of reagents. Cultivated on organic-based and chemically defined media (14 days at 28 to $30 \mathrm{C}$, $\alpha$-dimethylnaphthylamine-sulfanilic acid, $\mathrm{Zn}$ dust reagents).

Streptomyces albus (Rossi-Doria) Waksman and Henrici, Strain ATCC 3004 (IMRU 3004).

Spore ornamentation, shape, and dimensions: Smooth-walled, catenulate, elongated, ovoid, ca. 1.25 by $1.75 \mu$.

Morphology of sporophores: Compact or extended coiled chains of spores occurring on relatively short branches on rather long axial hyphae. Branches occur singly, oppositely branched, and sometimes in verticils which are difficult to detect.

Color of sporulating aerial mycelium: Cretaceous (chalk-white) after 14 days growth at 28 to $30 \mathrm{C}$ on Czapek's solution agar, inorganic salts-starch agar, and glycerol-asparagine agar. Cultures may also form near Pale Pinkish Buff $17^{\prime \prime}$ to Pale Pinkish Cinnamon 15" (Ridgway, Plate XXIX) colored aerial mycelium (ISCCNBS designation: 73. pale orange yellow), giving a pink tinge to an otherwise cretaceous appearance. 
Color of reverse of culture: Tints and shades of yellow, yellowish pink, orange yellow, and greenish yellow; Pale Ochraceous Buff $15^{\prime}$ (Ridgway, Plate XV; ISCC-NBS designation: 28. light yellowish pink), after 14 days growth on glycerol-asparagine agar at 28 to $30 \mathrm{C}$.

Chromogenicity: Nonchromogenic; forms no diffusible pigment when cultivated in tryptoneyeast extract broth with shaking for $48 \mathrm{hr}$ at 28 to $30 \mathrm{C}$, in $12 \%$ plain gelatin for 14 days at 28 to $30 \mathrm{C}$, on $15 \%$ gelatin or $15 \%$ gelatin- $1 \%$ starch for 14 days at $18 \mathrm{C}$, on white potato plugs for 14 days at 28 to $30 \mathrm{C}$, on $0.1 \% \mathrm{~L}(-)$-tyrosinewater agar for 14 days at 28 to $30 \mathrm{C}$, or on international peptone agar for 4 days at 28 to $30 \mathrm{C}$.

Production of hydrogen sulfide: Negative; no bluish-black coloration of substrate when cultivated for 10 days at 28 to $30 \mathrm{C}$ on peptone iron agar supplemented with $0.1 \%$ yeast extract.

Proteolysis: Positive; $12 \%$ plain gelatin liquefied after 14 days at 28 to $30 \mathrm{C}, 15 \%$ plain gelatin or $15 \%$ plain gelatin- $1 \%$ starch liquefied after 15 days at $18 \mathrm{C}$, skim milk peptonized after 14 days at 28 to $30 \mathrm{C}$, and casein agar cleared after 14 days at 28 to $30 \mathrm{C}$.

Amylolysis: Negative; inorganic salts-starch agar not cleared, and negative Lugol iodine reaction after 14 days at 28 to $30 \mathrm{C}$.

Utilization of carbon compounds: On Pridham and Gottlieb basal agar, after 10 days incubation at 28 to $30 \mathrm{C}$, good growth is shown on D-glucose, lactose, maltose, D-mannitol, and salicin. Fair growth on D-xylose. Poor growth on D-fructose. Very faint growth on L-arabinose, rhamnose, sucrose, raffinose, and $i$-inositol.

Utilization of sucrose in Czapek's solution agar: Negative; very poor growth.

Antagonistic properties: None.

Characteristic features: Catenulate, smoothwalled, ovoidal spores; coiled sporophores; cretaceous (often with tinges of pink) sporulating aerial mycelium; nonchromogenic; inability to hydrolyze starch; inability to form antibiotic factors.

Source or habitat: A descendant of a culture, originally isolated by Berestnev and labeled "albus"; obtained successively through the Kral, Pribram, and Institute of Microbiology, Rutgers University collections. Presumably first isolated from straw in Prague, Czechoslovakia about 1897 .

Optimal temperature range: Good vegetative growth and formation of aerial mycellium at $25 \mathrm{C}$ through $44 \mathrm{C}$; fair at $18 \mathrm{C}$; very poor at $55 \mathrm{C}$.

Related strains: Strains of streptomycetes that are closely related to this strain have been reported as isolated from or near beehives, from cases of dental caries, and from cases of human actinomycosis. Strain ATCC 3004 is maintained at the American Type Culture Collection, Washington, D. C., as ATCC 3004, and at the Institute of Microbiology, Rutgers University, New Brunswick, New Jersey, as IMRU 3004.

\section{DISCUSSION}

The 17 strains labeled "albus" that we have studied were originally relegated in our filing system to a group characterized by coiled sporophores, white aerial mycelium, inability to produce hydrogen sulfide, ability to utilize D-xylose, and inability to utilize L-arabinose and rhamnose. This filing system apparently is valid for this particular group, as evidenced by the results of this current study. Except for ability to produce antibiotic factors, all of the strains have been shown to be essentially identical. However, if the criteria outlined here are used, it would be difficult to identify any given strain within the group without resorting to study of antibiotic production.

We believe that the Waksman and Henrici description of $S$. albus should be accepted, and that our proposal to designate strain ATCC 3004 (IMRU 3004) as the neotype strain will place streptomycete taxonomy on a firmer foundation. There yet remains the issue of clarification of the status of the type species of the genus $\mathrm{No}$ cardia, i.e., Nocardia farcinica Trevisan.

We should like to emphasize that designation of strain ATCC 3004 (IMRU 3004) as the neotype strain of $S$. albus, or characterization of the 17 strains we have studied, does not establish the limits of the species. Indeed, we believe that the species limits are much broader than are exhibited by the aggregate of the 17 strains. These 17 probably represent one, or possibly two, subspecies within the species.

\section{ACKNOWLEDGMENTS}

Determining the histories of strains ATCC 618 and ATCC 3004 (IMRU 3004) has required considerable correspondence and discussion. We are grateful to the following for their as- 
sistance in this regard: S. A. Waksman, Institute of Microbiology, Rutgers University; W. A. Clark, Director, American Type Culture Collection; and G. A. de Vries, Centraalbureau voor Schimmelcultures, Baarn, Holland. We should like also to thank R. E. Buchanan and E. F. Lessel, Jr., Iowa State University, Ames, Iowa, for their assistance in preparation of this manuscript.

Supported, in part, by a grant from the Subcommittee on Taxonomy of the Actinomycetes of the Committee on Taxonomy of the American Society for Microbiology.

\section{LITERATURE CITED}

Committee on Bacteriological Technic. 1946. A manual of methods for pure culture study of bacteria. Biotech. Publications, Geneva, N. Y.

Gordon, R. E., AND J. M. Minm. 1957. A comparative study of some strains received as $\mathrm{No}$ cardiae. J. Bacteriol. 73:15-27.

Gordon, R. E., AND M. M. Smith. 1955. Proposed group of characters for the separation of Streptomyces and Nocardia. J. Bacteriol. 69: 147-150.

Hesseltine, C. W., R. G. Benedict, and T. G. Pridham. 1954. Useful criteria for species differentiation in the genus Streptomyces. Ann. N. Y. Acad. Sci. 60:136-151.

Kelly, K. L., ANd D. B. Judd. 1955. The ISCCNBS method of designating colors and a dictionary of color names. Circular 553, U. S. Department of Commerce, Washington, D. C.

KÜSTER, E. 1958. Final plan for international common experiment on characterization of streptomycetes. Processed in multilith form. $4 \mathrm{p}$.

Pridham, T. G. 1959. Retrospections on streptomycete taxonomy. Rev. latinoam. microbiol., Suppl. 3:1-22.

Pridham, T. G., P. Anderson, C. Foley, L. A. Lindenfelser, C. W. Hesseltine, and R. G. Benedict. 1957. A selection of media for maintenance and taxonomic study of Streptomyces. Antibiotics Ann. 1956-57, p. 947-953.

Pridham, T. G., and D. Gottlieb. 1948. The utilization of carbon compounds by some Actinomycetales as an aid for species determination. J. Bacteriol. 56:107-114.

Pridham, T. G., H. H. Hall, and M. C. Shekle-
Ton. 1951. The identification of some Actinomycetales with particular reference to isolates producing vitamin $\mathrm{B}^{12}$ and related growth factors. Bacteriol. Proc., p. 27-28.

Pridham, T. G., C. W. Hesseltine, and R. G. Benedict. 1958. A guide for the classification of streptomycetes according to selected groups. Placement of strains in morphological sections. Appl. Microbiol. 6:52-79.

Pridham, T. G., L. A. Lindenfelser, O. L. Shotwell, F. H. Stodola, R. G. Benedict, C. Foley, R. W. JACKSON, W. J. ZAUMEYER, W. H. Preston, JR., And J. W. Mitchell. 1956. Antibiotics against plant disease. I. Laboratory and greenhouse survey. Phytopathology 46:568-575.

PridhaM, T. G., ANd A. J. Lyons, JR. 1961. Streptomyces albus (Rossi-Doria) Waksman et Henrici: Taxonomic study of strains labelled Streptomyces albus. J. Bacteriol. 81: 431-441.

Ridgway, R. 1912. Color standards and color nomenclature. Published by the author, Washington, D. C.

Subcommitee on the Taxonomy of the ActiNOMYCETES. 1958. Methods for use in "Cooperative studies on criteria for description of the streptomycetes." D. Gottlieb, Chairman. Processed in multilith form. $17 \mathrm{p}$.

Tresner, H. D., ANd F. DAnga. 1958. Hydrogen sulfide production by Streptomyces as a criterion for species differentiation. J. Bacteriol. 76:239-244.

Tresner, H. D., M. C. Davies, and E. J. Backus. 1961. Electron microscopy of Streptomyces spore morphology and its role in species differentiation. J. Bacteriol. 81:70-80.

Waksman, S. A. 1919. Cultural studies of species of Actinomyces. Soil Sci. 8:71-215.

Waksman, S. A. 1961. The actinomycetes. Volume 2. Classification, identification and descriptions of genera and species. The Williams and Wilkins Company, Baltimore.

Waksman, S. A., And R. E. Curtis. 1916. The Actinomyces of the soil. Soil Sci. 1:99-134.

Waksman, S. A., And A. T. Henrici. 1943. The nomenclature ande lassification of the actinomycetes. J. Bacteriol. 46:337-341.

Warren, H. B., Jr., J. F. Prokop, and W. E. Grundy. 1955. Nonsynthetic media for antibiotic producing actinomycetes. Antibiotics \& Chemotherapy 5:6-12.

Wollenweber, H. W. 1920. Der Kartoffelschorf. Verlagsbuchhandlung Paul Parey, Berlin. 